\title{
Correlations between Pre-morbid Personality and Depression Scales in Stroke Patients
}

\author{
Sung Il Hwang, M.D., Kyung In Choi, M.D., Oak Tae Park, M.A., \\ Si-Woon Park, M.D. ${ }^{1}$, Eun Seok Choi, M.D. ${ }^{1}$, Sook-Hee Yi, M.D. ${ }^{2}$ \\ Department of Rehabilitation Medicine, National Rehabilitation Center, Seoul 142-070, \\ ${ }^{1}$ Myongji Choonhey Rehabilitation Hospital, Seoul 150-760, \\ ${ }^{2}$ Samsung Medical Center, Sungkyunkwan University School of Medicine, Seoul 135-710, Korea
}

Objective To investigate the correlation between pre-morbid personality and depression scales in patients with stroke.

Method The subjects of this study included 45 patients with stroke and their caregivers. We conducted an interview of patients with Beck Depression Inventory (BDI) and also evaluated general characteristic (age, sex, location of lesion, cause of stroke, duration of illness, educational background, history of medication for depression) and functional level. Caregivers were evaluated with Hamilton Rating Scale for Depression (HRSD) for depressive mood, with NEO-PI (Neuroticism, Extraversion and Openness Personality Inventory) for pre-morbid personality. The results of each questionnaire were analyzed in order to investigate their correlation. The results were statistically analyzed with independent t-test, ANOVA, and Pearson correlation test.

Results The HRSD score of the caregivers had a significant correlation with the BDI score $(\mathrm{p}=0.001)$ of the patients. The BDI score correlated with Neuroticism $(\mathrm{p}=0.021)$ and the HRSD score also correlated with Neuroticism ( $p=0.015)$. There were no statistical correlation of depression with sex, age, case of stroke, location of lesion, duration of illness and functional level.

Conclusion Among pre-morbid personalities, neuroticism of NEO-PI is the only factor which is significantly correlated with depression scales in stroke patients. Evaluating pre-morbid personality can be helpful in predicting the depressive mood in stroke patients, so we may have early intervention for it.

Key Words Stroke, Depression, Personality, Caregiver

Received July 6, 2010; Accepted January 24, 2011

Corresponding author: Kyung In Choi

Department of Rehabilitation Medicine, National Rehabilitation Center, 520, Suyu 5-dong, Gangbuk-gu, Seoul 142-070, Korea

Tel: +82-2-901-1670, Fax: +82-2-902-3835, E-mail: iamadreamer@naver. com

Copyright $\odot 2011$ by Korean Academy of Rehabilitation Medicine

\section{INTRODUCTION}

The psychological symptoms that may occur after stroke include depression, anger, aggression, anxiety, apathy, catastrophic reaction, psychosis and mania, ${ }^{1}$ of which the most common symptom is depression. ${ }^{2} 1 / 3-2 / 3$ of patients suffer from post-stroke depression, of which the main symptoms were reportedly loss of energy in $83 \%$ of patients, sleep disorder in $67 \%$, increase of brooding in $60 \%$, and hopelessness in $39 \%$. $^{3}$ 
Special attention is needed in post-stroke depression because it prevents patients from participating in active rehabilitation, resulting in the failure of rehabilitation. ${ }^{4}$ Studies show post-stroke depression attributes to the stroke itself, sequelae of stroke, risk factors of major depressive disorder, severe cognitive dysfunction and physical disability after stroke. ${ }^{5}$ Of the risk factors that predict major depressive disorder, women, family history, and past history are also reported major risk factors of post-stroke depression. ${ }^{6}$ Pre-morbid personality, in particular neuroticism, which is another risk factor of major depressive disorder, has received little attention. ${ }^{7,8}$ Relevant studies have been presented several times abroad, but there have been none in Korea.

This study was conducted to determine the correlation between pre-morbid personality and depression scales in stroke patients. Furthermore, its correlation with location of lesion, sex, functional ability, age, cause of stroke, duration of illness (months), presence of underlying disease, educational background, and history of medication for depression was also investigated.

\section{MATERIALS AND METHODS}

\section{Subjects}

The study included 45 patients who were admitted to our department for stroke from January 2009 to September 2009. Those patients who could not conduct ' 3 step obey', those with aphasia, and those who suffered other psychological diseases before stroke were excluded. Selected caregivers were restricted to those who had known the patients before stroke and had visited the patients at least once a week.

\section{Methods}

Evaluating depression scale: To evaluate the subject's depression scale, BDI (Beck's depression index) standardized by Lee et al. ${ }^{9}$ was used. The score range was from 0 to 3 . With 21 questions in total, 63 was the maximum score. In BDI, generally a person scoring more than 20 was identified as suffering from depression. ${ }^{9}$ However, depression was specified further as mild, moderate, severe and is open to changes according to other variables such as age. Therefore, this study did not use cut off value, but raw scores. Moreover, when measuring caregivers with HRSD (Hamilton rating scale for depression), the three categories (psychomotor retardation, agitation, insight) that required a direct evaluation of testers were excluded, results were also given in raw scores.

Evaluating pre-morbid personality: To evaluate premorbid personality, NEO-PI (Neuroticism, Extraversion and Openness Personality Inventory $)^{10}$ standardized by Kang ${ }^{11}$ was used. It consists of 50 questions, with 4 scores each, and was convenient for patients and their caregivers to evaluate themselves. This test was used on caregivers who were evaluated with HRSD.

Others: General characteristics of patients (age, sex, location of lesion, cause of stroke, duration of illness, level of education, history of medication for depression) and functional level; K-MBI (Korean Modified Barthel Index), HMS (Hand Movement Scale), FAC (Functional Ambulatory Category); were also assessed.

\section{Statistical analysis}

Data was analyzed by SPSS for Windows version 12.0 (SPSS Inc., Chicago, USA), and statistical level of significance was controlled to less than 0.05. Pearson correlation analysis was performed in order to find the correlation between pre-morbid personality and depression scales, between the HRSD score of the caregivers and the BDI score of the patients. The correlation between depression scale and other factors (age, sex, location of lesion, causes of stroke, duration of illness, presence of underlying disease, education background, usage of depression drugs, physical function level) were also investigated, using student t-test and one-way ANOVA according to the factor's number of parameters. Moreover, parameters that were reported to be statistically significant were analyzed with multiple regression analysis.

\section{RESULTS}

\section{General characteristics of patients (Table 1)}

The average age of onset was $47.56 \pm 11.23$ (range 2762 ). Out of the 45 patients, 28 were male and 17 were female. The cause of stroke were found to be cerebral infarction in 22 patients, cerebral hemorrhage in 23 , right hemiplegia in 13 , left hemiplegia in 26 , and quadriplegia in 6 . The duration of illness averaged 6.7 months, and 25 patients had underlying diseases while 20 did not. 
Table 1. General Characteristics of Patients

\begin{tabular}{|llc|}
\hline & Characteristics & $\begin{array}{c}\text { Number } \\
\text { of cases }\end{array}$ \\
\hline Sex & Man & 28 \\
\hline Age (years) & Woman & 17 \\
\hline Cause of stroke & $47.56 \pm 11.23$ & \\
\hline Location of lesion & Infarction & 22 \\
\hline & Remorrhage & 23 \\
\hline Duration of illness & Left & 26 \\
\hline (months) & Both & 13 \\
\hline & $4-3$ & 6 \\
\hline Underlying disease & $7-12$ & 15 \\
\hline & $>13$ & 15 \\
\hline MMSE & Presence & 9 \\
\hline Educational background & Absence & 6 \\
\hline & $25.93 \pm 3.83$ & 25 \\
\hline & Middle school & 5 \\
\hline History of medication for & Present & 18 \\
\hline depression & Absh school & 18 \\
\hline & Absent & 10 \\
\hline
\end{tabular}

MMSE : mini-mental state exam

A total of 4 patients had graduated from elementary school, 5 from middle school, 18 from high school, and 18 from university including technical college. Ten patients had been administered depression drugs. Specifically, 7 patients were taking SSRI (1 paroxetine, 3 fluoxetine, 2 sertraline, 1 escitalopram), 2 were taking SNRI (milnacipran), and 1 was taking an atypical antidepressant (bupropion).

Age and depression scale: There was no significant correlation in age and Beck's depression index ( $\mathrm{r}=0.157$, $\mathrm{p}=0.303$ ), but there was significant correlation in age and Hamilton rating scale for depression $(r=0.303, p=0.042)$.

Sex and depression scale: In BDI, the average score of males was $11.86 \pm 8.62$, and that of females was $14.94 \pm 7.54$, which were statistically insignificant ( $\mathrm{p}=0.230)$. In HRSD, the average score of males was $8.96 \pm 6.23$, and that of females was $9.29 \pm 5.91$, which were also statistically insignificant in independent $\mathrm{t}$-test $(\mathrm{p}=0.860)$.
The causes of stroke and depression scale: In BDI, the average score of patients with cerebral hemorrhage was $12.83 \pm 8.23$ and the average score of patients with cerebral infarction was $13.23 \pm 8.52$, which were statistically insignificant ( $\mathrm{p}=0.873)$. In HRSD, the average scores of patients with hemorrhage and infarction were 9.91 \pm 5.92 and $8.28 \pm 6.20$, respectively, which were of insignificant $(\mathrm{p}=0.356)$.

Location of lesion and depression scale: In BDI, the average score of patients with right hemiplegia was $10.54 \pm 7.02$, that of patients with left hemiplegia was $14.88 \pm 8.97$, and that of patients with quadriplegia was $10.33 \pm 6.31$ which had no statistical significance $(p=0.214)$. The average HRSD score of patients with right hemiplegia was $9.46 \pm 4.63$, that of patients with left hemiplegia was $8.77 \pm 6.20$, and that of patients with quadriplegia was $9.09 \pm 6.05$ again having no statistical significance $(\mathrm{p}=0.919)$.

Duration of illness and depression scale: No statistical significance was found in both BDI and duration of illness which were classified into 4 groups $(\mathrm{p}=0.594)$. HRSD showed the same result of having no statistical significance with duration of illness $(\mathrm{p}=0.799)$.

MMSE (mini-mental state exam) and depression scale: The MMSE average score of patients $25.93 \pm 3.83$, having no correlation with BDI $(\mathrm{r}=0.078, \mathrm{p}=0.610)$, but not with $\operatorname{HRSD}(\mathrm{r}=-0.229, \mathrm{p}=0.130)$.

Education background and depression scale: The average BDI score of patients who had finished primary school was $19.25 \pm 7.04$, that of patients who had graduated from middle school was $7.80 \pm 3.96$, that of patients who had graduated from high school was $14.33 \pm 9.14$, and that of patients who had graduated from university was $11.78 \pm 7.80$, showing no statistical significance $(\mathrm{p}=0.163)$. The average HRSD score of patients who had finished primary school was $12.25 \pm 4.43$, that of patients who had graduated from middle school was $12.80 \pm 2.39$, that of patients who had graduated from high school was $8.50 \pm 6.65$, and that of patients who had graduated from university was $7.94 \pm 6.12$, again showing no statistical significance $(\mathrm{p}=0.291)$.

Usage of depression drugs and depression scale: The average BDI score of patients who were taking depression drugs was $13.00 \pm 8.67$, and that of those patients who were not taking such drugs was $13.03 \pm 8.30$, which were statistically insignificant $(p=0.993)$. The average HRSD 
score of patients who were taking depression drugs was $10.20 \pm 5.24$, and that of those who were not taking such drugs was $8.77 \pm 6.30$, again statistically insignificant $(\mathrm{p}=0.478)$.

K-MBI, HMS, FAC assessed physical function level and depression scale: In case of quadriplegia, the more severely damaged parts were mainly assessed. K-MBI showed a wide range of scores from 10 to 100 , not correlating with BDI $(\mathrm{r}=-0.237, \mathrm{p}=0.116)$ nor HRSD

Table 2. Correlation between Factors and Depression Scales

\begin{tabular}{lcc}
\hline & $\begin{array}{c}\text { BDI } \\
\text { (p-value) }\end{array}$ & $\begin{array}{c}\text { HRSD } \\
\text { (p-value) }\end{array}$ \\
\hline Sex & 0.230 & 0.860 \\
\hline Age (years) & 0.303 & $0.042^{*}$ \\
\hline Cause of stroke & 0.873 & 0.356 \\
\hline $\begin{array}{l}\text { Location of lesion } \\
\begin{array}{l}\text { Duration of illness } \\
\text { (months) }\end{array}\end{array}$ & 0.214 & 0.919 \\
\hline MMSE & 0.594 & 0.799 \\
$\begin{array}{l}\text { Educational } \\
\text { background }\end{array}$ & 0.610 & 0.130 \\
\hline $\begin{array}{l}\text { History of } \\
\text { medication for } \\
\text { depression }\end{array}$ & 0.163 & 0.291 \\
\hline $\begin{array}{l}\text { Functional ability } \\
\text { K-MBI }\end{array}$ & 0.993 & 0.478 \\
\hline HMS & 0.116 & \\
\hline FAC & 0.192 & 0.192 \\
\hline
\end{tabular}

BDI: Beck's depression index, HRSD: Hamilton rating scale for depression, K-MBI: Korean Modified Barthel Index, HMS: Hand Movement Scale, FAC: Functional Ambulatory Category

*Correlation is statistically significant at the 0.05 level (2-tailed) $(\mathrm{r}=-0.198, \mathrm{p}=0.192)$. HMS also did not correlate with BDI ( $\mathrm{p}=0.192)$ nor HRSD. FAC did not correlate with BDI $(\mathrm{p}=0.201)$, nor HRSD $(\mathrm{p}=0.283)$ (Table 2$)$.

\section{The correlation of BDI with HRSD}

BDI and HRSD showed valid correlation (Table 3).

The correlation between depression and pre-morbid personality

Among the types of NEO-PI, BDI showed no statistical correlation with $\mathrm{E}$ (extraversion), O (openness to experience), A (agreeableness), C (conscientiousness). The only type of personality that correlated statistically with BDI was $\mathrm{N}$ (neuroticism). The results were same with the correlation with HRSD. Therefore, it could be concluded that post-stroke depression and neuroticism are correlated with each other (Table 4).

\section{Multiple regression analysis of the main parameters}

$\mathrm{N}$ (neuroticism) and basic information such as age and sex were results that were significant in univariate study, and the adaptation to ordinary life, usage of depression drugs, and duration of illness were reported as significant in other reports. Therefore, these factors were used as standards for measuring depression scales for multiple regression analysis. In regards to BDI N (neuroticism), sex, age, K-MBI, usage of depression scale, and duration

Table 3. Correlation of BDI and HRSD

\begin{tabular}{llc} 
& & HRSD \\
\hline BDI & Pearson coefficient $(\mathrm{r})$ & $0.495^{*}$ \\
$(\mathrm{~N}=45)$ & $\mathrm{p}$-value & 0.001 \\
\hline
\end{tabular}

BDI: Beck's depression index, HRSD: Hamilton rating scale for depression

*Correlation is statistically significant at the 0.001 level (2-tailed)

Table 4. Correlation of Post-Stroke Depression and Pre-Morbid Personality

\begin{tabular}{lllrrrr}
\hline & & N & E & O & \multicolumn{1}{c}{ A } & \multicolumn{1}{c}{ C } \\
\hline BDI & Pearson coefficient (r) & $0.342^{*}$ & 0.103 & -0.084 & -0.231 & -0.194 \\
$(\mathrm{~N}=45)$ & p-value & 0.021 & 0.501 & 0.583 & 0.128 & 0.201 \\
HRSD & Pearson coefficient (r) & $0.358^{*}$ & -0.174 & -0.185 & -0.147 & -0.056 \\
$(\mathrm{~N}=45)$ & p-value & 0.016 & 0.254 & 0.225 & 0.336 & 0.717 \\
\hline
\end{tabular}

N: Neuroticism, E: Extraversion, O: Openness to experience, A: Agreeableness, C: Conscientiousness, BDI: Beck's depression index, HRSD: Hamilton rating scale for depression

${ }^{*}$ Correlation is statistically significant at the 0.05 level (2-tailed) 
Table 5. Multiple Regression Analysis of Post-Stroke Depression

\begin{tabular}{lcc}
\hline & $\begin{array}{c}\text { BDI } \\
\text { (p-value) }\end{array}$ & $\begin{array}{c}\text { HRSD } \\
\text { (p-value) }\end{array}$ \\
\hline Neuroticism & $0.014^{*}$ & $0.015^{*}$ \\
Sex & 0.073 & 0.736 \\
\hline Age (years) & 0.141 & 0.055 \\
K-MBI & 0.203 & 0.164 \\
$\begin{array}{l}\text { History of medication } \\
\text { for depression }\end{array}$ & 0.569 & 0.934 \\
Duration & 0.422 & 0.275 \\
\hline
\end{tabular}

K-MBI: Korean Modified Barthel Index, BDI: Beck's depression index, HRSD: Hamilton rating scale for depression

*Correlation is statistically significant at the 0.05 level (2-tailed)

of illness, there were no multicollinearity (Durbin-Watson value: 1.612), and were only significantly correlated with neuroticism. The results were same with HRSD. There were no multicollinearity (Durbin-Watson value: 1.676), and its correlation was only valid with neuroticism (Table 5).

\section{DISCUSSION}

According to the study of Robinson et al. ${ }^{12}$ in 1983 with DSM-III, post-stroke depression has $27 \%$ probability of leading to major depressive disorder and $20 \%$ to dysthymia. In the study by Astrom et al. ${ }^{13}$ in $1993,25 \%$ of 73 patients were diagnosed with depression by DSMIII. Another study, the lowest prevalence rates were depressive disorder found in patients that studied in community settings where $14 \%$ of the patients were found to have major depression, while $9 \%$ had minor depression. In outpatient settings, which vary between 3 months and 3 or more years following stroke, the prevalence rate for major depression was $24.0 \%$, and for minor depression was $23.9 \% .{ }^{14}$ Suicide ideation or pessimism is less frequently seen than apathy, which often demotivates people, in depression. ${ }^{15,16}$

Lack of energy and depressive moods are one of the major symptoms of depression. In physical terms, cognitive dysfunction or psychological symptoms arouses, distracting people from living an ordinary life. The study conducted by Pyun and $\mathrm{Kim}^{17}$ revealed that a person's adaption of living everyday life was significantly higher when he did not suffer depression. Another study ${ }^{4}$ relating depression and the result of rehabilitation showed that depression discourages people from participating in active rehabilitation, reducing the probability of achieving the originally aimed goal of rehabilitation. Because depression is a chronic disorder, post-stroke depression is prone to occur at any time. This is problematic not only to the individual but also to the family, eventually expanding as a problem for the whole society. If post-stroke depression were predictable in advance, close observation and support may be given. Special treatment such as education of caregivers, psychological therapy and preventive medication can be also provided. Early detection and treatment of depression is important in the sense that it enables better comprehensive rehabilitation results of not only depression but also stroke.

The most widespread way to determine depression is DSM-IV (Diagnostic and Statistical Manual of Mental Disorders, Fourth Edition), but its drawback remains that quantitative analysis is impossible and it requires specialists. Aben et al., ${ }^{18}$ reported that HRSD is most similar to DSM-IV and the highest sum of sensitivity and specificity, and that although BDI, HADS (Hospital Anxiety and Depression Scale), SCL-90, and HRSD differ in terms of sensitivity and specificity, they are all valid as screening tests. BDI is commonly used for its timeefficiency and a small number of questions that reduce confusion in patients. ${ }^{9}$

Depression among patients with stroke was studied in relation to its correlation with other factors. The study of Robinson et al. ${ }^{19}$ concluded that patients with damaged frontal lobe had higher possibilities of suffering poststroke depression. Moreover, the study of Morris et al. ${ }^{20}$ agreed to this conclusion, reporting that patients with damaged left hemisphere, the frontal lobe and basal ganglia in particular, suffered more severe depression. The study of Carson et al., ${ }^{21}$ however, suggested that the location of lesion and post-stroke depression did not correlate. The effect of gender on the diseases is also controversial. While Paolucci et al. ${ }^{22}$ maintained that patients with cerebrovascular disease are at a much higher risk, Kaji et al. ${ }^{23}$ found no statistical correlation. This study also failed in discovering any correlation of depression with the damaged part in cerebrum or gender. Personality traits are integral and organized behaviors 
that characterize an individual. This refers to the reactions of an individual to diverse circumstances, specifically those with stability and consistency, making it appropriate for deduction. There are 5 classifications that show both personality traits common in most humans and differences among individuals. We conducted this study based on the Big Five Structure/Five Factor Model, which shows that the personality traits of individuals is divided largely into 5 factors. ${ }^{24-28}$

There are studies presented abroad showing that $\mathrm{N}$ (neuroticism), one of the 5 factors, is closely related to post-stroke depression, ${ }^{29-31}$ but there have been no studies like this in Korea. This is most likely because there are not many tests that can be used for practical medical purposes rather than mere evaluation of personality. NEO-PI ${ }^{10}$ was selected carefully among tests that fulfilled the following conditions: differentiates of the 5 personality traits, quantitative analysis is possible, has a comparatively short measuring time, is easy for those at low cognitive level to understand, and is confirmed after translated into Korean. In Korea, the translation modified into by Kang ${ }^{11}$ (N: neuroticism, E: extraversion, $\mathrm{O}$ : openness to experience, A: agreeableness, C: conscientiousness) (Appendix 1) was used.

NEO-PI was used in a variety of areas, studying borderline personality disorder and paranoid personality disorder had a positive correlation with neuroticism (N), schizotypal personality disorder positively correlated with neuroticism (N) and negatively correlation with extraversion (E).$^{32}$ In addition, it was reported that anxiety and schizophrenia have a positive correlation with neuroticism $(\mathrm{N})$, mania has a positive correlation with extraversion (E), paranoia and antisocial personality have a negative correlation with agreeableness $(\mathrm{A}){ }^{33}$

This is because neuroticism (N) is defined as a personality trait that accumulates negative emotions (fear, anger, frustration). ${ }^{10,29}$ High neuroticism (N) is generally associated with being emotionally anxious, displaying hostility towards others, and being sensitive to what others think. ${ }^{33}$ This contributes to making a response to the changed appearance after stroke the most depressed compared to other types of traits.

The limitations of this study included a small number of subjects which made generalization difficult. Also, there were relatively more patients with damage in the left cerebral hemisphere, which is the result of excluding patient subjects of severe cognitive and communication dysfunction. Premorbid personality was not determined by NEO-PI based on the supposition that some change would take place in the patient, but there lies the possibility that a disparity may exist between the caregivers witness and the patients real personality before stroke. It is helpful, however, in the sense that screening tests can be done when patients are hospitalized and there is active rehabilitation when neuroticism is identified through the test.

\section{CONCLUSION}

Through this study, we found that in predicting depression of patients with stroke, knowing pre-morbid personality measured with NEO-PI is more helpful than knowing age, sex, causes of stroke, location of lesion, duration of illness, presence of underlying disease, education background, usage of depression drugs, or physical viability. Furthermore, not only BDI evaluated directly by the patient but also HRSD evaluated by intimate caregivers showed the correlation between premorbid personality and post-stroke depression scale. This conclusion signifies that premorbid personality helps predict depression, and that psychological and emotional support can be designed in a more specific manner along with medical treatment. Therefore, this should be considered seriously when setting rehabilitation goals of patients with stroke.

\section{REFERENCES}

1. Kim JM, Shin HY. Diagnosis and treatment of poststroke depression. Korean J Biol Psychiatry 2005; 12: 89-97

2. Angelelli P, Paolucci S, Bivona U, Piccardi L, Ciurli P, Cantagallo A, Antonucci G, Fasotti L, Di Santantonio A, Grasso MG, et al. Development of neuropsychiatric symptoms in poststroke patients: a cross-sectional study. Acta Psychiatri Scand 2004; 110: 55-63

3. Richard LH, Elliot JR, David Y. Rehabilitation in stroke syndromes. In: Braddom RL, Editor. Physical medicine and rehabilitation, 3rd ed, Philadelphia: Sauders, 2007, 1195

4. Cicerone KD, Dahlberg C, Kalmar K, Langenbahn DM, Malec JF, Bergquist TF, Felicetti T, Giacino JT, 
Harley JP, Harrington DE, et al. Evidence-based cognitive rehabilitation: recommendations for clinical practice. Arch Phys Med Rehabil 2000; 81: 1596-1615

5. Downhill JE Jr, Robinson RG. Longitudinal assessment of depression and cognitive impairment following stroke. J Nervous Ment Dis 1994; 182: 425-431

6. Gall, A. Post stroke depression. Hosp Med 2001; 62: 268-273

7. Hirschfeld RM, Klerman GL, Lavori P, Keller MB, Griffith P, Coryell W. Premorbid personality assessments of first onset of major depression. Arch Gen Psychiatry 1989; 46: 345-350

8. Widiger TA, Trull TJ. Personality and psychopathology: an application of the five-factor model. J Pers 1992; 60: 363-393

9. Lee MK, Lee YH, Park SH, Sohn CH, Jung YJ, Hong SK, Lee BK, Jang PL, Yun AL. A standardization study of beck depression inventory (I): Korean version (K-BDI): reliability land factor analysis. Korean J Psychopathol 1995; 4: 77-95

10. Piedmont RL, McCrae RR, Costa PT Jr. An assessment of the Edwards Personal Preference Schedule from the perspective of the five-factor model. J Pers Assess 1992; 58: 67-78

11. Kang YS. A study on disturbing behaviors of demented elderly staying at home. [dissertation] Busan: Pusan National University, 2000

12. Robinson RG, Starr LB, Kubos KL, Price TR. A twoyear longitudinal study of post-stroke mood disorders: findings during the initial evaluation. Stroke 1983; 14: 736-741

13. Astrom M, Adolfsson R, Asplund K. Major depression in stroke patients. A 3-year longitudinal study. Stroke 1993; 24: 976-982

14. Robinson RG, Spalletta G. Poststroke depression: a review. Can J Psychiatry 2010; 55: 341-349

15. Lipsey JR, Spencer WC, Rabins PV, Robinson RG. Phenomenological comparison of poststroke depression and functional depression. Am J Psychiatry 1986; 143: 527-529

16. Jorge RE, Starkstein SE, Robinson RG. Apathy following stroke. Can J Psychiatry 2010; 55: 350-354

17. Pyun SB, Kim SJ. Life satisfaction of individuals with disabling conditions. J Korean Acad Rehab Med 1994; 18: $532-543$

18. Aben I, Verhey F, Lousberg R, Lodder J, Honig A.
Validity of the beck depression inventory, hospital anxiety and depression scale, SCL-90, and hamilton depression rating scale as screening instruments for depression in stroke patients. Psychosomatics 2002; 43: $386-393$

19. Robinson RG, Kubos KL, Starr LB, Rao K, Price TR. Mood disorders in stroke patients. Importance of location of lesion. Brain 1984; 107: 81-93

20. Morris P, Robinson RG, Raphael B. Prevalence and course of depressive disorders in hospitalized stroke patients. Int J Psychiatry Med 1990; 20: 349-364

21. Carson AJ, MacHale S, Allen K, Lawrie SM, Dennis M, House A, Sharpe M. Depression after stroke and lesion location: a systematic review. Lancet 2000; 356: 122-126

22. Paolucci S, Gandolfo C, Provinciali L, Torta R, Sommacal S, Toso V. Quantification of the risk of post stroke depression: the Italian multicenter observational study DESTRO. Acta Psychiatr Scand 2005; 112: 272-278

23. Kaji Y, Hirata K, Ebata A. Characteristics of post-stroke depression in Japanese patients. Neuropsychobiology 2006; 53: 148-152

24. Botwin MD, Buss DM. Structure of act-report data: is the five-factor model of personality recaptured? J Pers Soc Psychol 1989; 56: 988-1001

25. Draper TW, Holman TB. Locating the big five personality factors in the relate relationship evaluation measures. Psychol Rep 2005; 97: 877-886

26. Peabody D, Goldberg LR. Some determinants of factor structures from personality-trait descriptors. J Pers Soc Psychol 1989; 57: 552-567

27. Goldberg LR. An alternative "description of personality": the big-five factor structure. J Pers Soc Psychol 1990; 59: 1216-1229

28. McCrae RR, Costa PT Jr. Validation of the fivefactor model of personality across instruments and observers. J Pers Soc Psychol 1987; 52: 81-90

29. Aben I, Lodder J, Honig A, Lousberg R, Boreas A, Verhey $F$. Focal or generalized vascular brain damage and vulnerability to depression after stroke: a 1-year prospective follow-up study. Int Psychogeriatr 2006; 18: $19-35$

30. Aben I, Denollet J, Lousberg R, Verhey F, Wojciechowski F, Honig A. Personality and vulnerability to depression in stroke patients: a 1-year prospective 
follow-up study. Stroke 2002; 33: 2391-2395

31. Greenop KR, Almeida OP, Hankey GJ, van Bockxmeer F, Lautenschlager NT. Premorbid personality traits are associated with post-stroke behavioral and psychological symptoms: a three-month follow-up study in Perth, Western Australia. Int Psychogeriatr 2009; 21: 1063-1071

32. Costa PT Jr, McCrae RR. Domains and facets: hierar- chical personality assessment using the revised NEO personality inventory. J Pers Assess 1995; 64: 21-50

33. Hopwood CJ, Morey LC, Ansell EB, Grilo CM, Sanislow CA, McGlashan TH, Markowitz JC, Gunderson JG, Yen S, Shea MT, et al. The convergent and discriminant validity of five-factor traits: current and prospective social, work, and recreational dysfunction. J Pers Disord 2009; 23: 466-476 
Appendix 1. NEO-PI Questionnaire of Pre-morbid personality

\begin{tabular}{lcccc}
\hline \multicolumn{1}{c}{ Contents } & $\begin{array}{c}\text { Very } \\
\text { much }\end{array}$ & Much & Little & None \\
\hline 1. Basically anxious & 4 & 3 & 2 & 1 \\
2. Is straightforward & 4 & 3 & 2 & 1 \\
3. Is ambitious & 4 & 3 & 2 & 1 \\
4. Is forgiving & 4 & 3 & 2 & 1 \\
5. Is fastidious & 4 & 3 & 2 & 1 \\
$\begin{array}{l}\text { 6. Overreactive to } \\
\text { frustration, irritable }\end{array}$ & 4 & 3 & 2 & 1 \\
$\begin{array}{l}\text { 7. Is voluntary } \\
\text { 8. Is imaginative }\end{array}$ & 4 & 3 & 2 & 1 \\
$\begin{array}{l}\text { 9. Is not dubious of } \\
\text { others }\end{array}$ & 4 & 3 & 2 & 1 \\
\hline
\end{tabular}

$\begin{array}{lllll}\text { 10. Clearcut, consistent } & 4 & 3 & 2 & 1\end{array}$

$\begin{array}{lllll}\text { 11. Easily loses temper } & 4 & 3 & 2 & 1 \\ \text { 12. Gregarious } & 4 & 3 & 2 & 1 \\ \text { 13. Is idealistic } & 4 & 3 & 2 & 1 \\ \text { 14. Loves peace } & 4 & 3 & 2 & 1 \\ \text { 15. Orderly } & 4 & 3 & 2 & 1 \\ \text { 16. Is impatient } & 4 & 3 & 2 & 1 \\ \text { 17. Is enthusiastic } & 4 & 3 & 2 & 1 \\ \text { 18. Is creative } & 4 & 3 & 2 & 1 \\ \text { 19. Has warmth, } & 4 & 3 & 2 & 1\end{array}$

compassionate

$\begin{array}{lllll}\text { 20. tries his best } & 4 & 3 & 2 & 1 \\ \text { 21. Is easily upset } & 4 & 3 & 2 & 1 \\ \text { 22. Is active } & 4 & 3 & 2 & 1 \\ \text { 23. Has many talents } & 4 & 3 & 2 & 1 \\ \text { 24. Is tolerant } & 4 & 3 & 2 & 1 \\ \text { 25. Is industrious } & 4 & 3 & 2 & 1 \\ \text { 26. Fluctuating moods } & 4 & 3 & 2 & 1 \\ \text { 27. Is bald } & 4 & 3 & 2 & 1 \\ \text { 28. Has insight into } & 4 & 3 & 2 & 1 \\ \text { matters } & & & & \end{array}$

29. Behaves in $\quad \begin{array}{lllll}4 & 3 & 2 & 1\end{array}$

sympathetic manner

$\begin{array}{lllll}\text { 30. Is progressive } & 4 & 3 & 2 & 1 \\ \text { 31. Critical, skeptical } & 4 & 3 & 2 & 1 \\ \text { 32. Is enterprising } & 4 & 3 & 2 & 1 \\ \text { 33. Has wide range of } & 4 & 3 & 2 & 1\end{array}$
interests

\begin{tabular}{lllll} 
34. Is hairsplitting & 4 & 3 & 2 & 1 \\
35. Is persevering & 4 & 3 & 2 & 1 \\
\hline
\end{tabular}

Appendix 1. Continued

\begin{tabular}{lcccc}
\multicolumn{1}{c}{ Contents } & $\begin{array}{c}\text { Very } \\
\text { much }\end{array}$ & Much & Little & None \\
\hline $\begin{array}{l}\text { 36. Concerned with own } \\
\text { adequacy }\end{array}$ & 4 & 3 & 2 & 1 \\
$\begin{array}{l}\text { 37. Is energetic } \\
\text { 38. Is inquisitive }\end{array}$ & 4 & 3 & 2 & 1 \\
$\begin{array}{l}\text { 39. Is boastful } \\
\text { 40. Is productive }\end{array}$ & 4 & 3 & 2 & 1 \\
$\begin{array}{l}\text { 41. Tends to be self- } \\
\text { defensive }\end{array}$ & 4 & 3 & 2 & 1 \\
$\begin{array}{l}\text { 42. Skilled in play and } \\
\text { humor }\end{array}$ & 4 & 3 & 2 & 1 \\
$\begin{array}{l}\text { 43. Has unconventional } \\
\text { thought processes }\end{array}$ & 4 & 3 & 2 & 1 \\
$\begin{array}{l}\text { 44. Is obstinate } \\
\text { 45. Is agitated }\end{array}$ & 4 & 3 & 2 & 1 \\
$\begin{array}{l}\text { 46. Has rapid personal } \\
\text { tempo }\end{array}$ & 4 & 3 & 2 & 1 \\
$\begin{array}{l}\text { 47. Is cheerful } \\
\text { 48. Is inattentive }\end{array}$ & 4 & 3 & 2 & 1 \\
$\begin{array}{l}\text { 49. Behaves in assertive } \\
\text { fashion }\end{array}$ & 4 & 3 & 2 & 1 \\
\begin{tabular}{l} 
50. Is impulsive \\
\hline
\end{tabular} & 4 & 3 & 2 & 1 \\
\hline
\end{tabular}

37. Is energeti

38. Is inquisitive

42. Skilled in play and

umor thought processe

44. Is obstinate

Is agitate

46. Has rapid persona
39. Is boastful

\begin{tabular}{lllll} 
47. Is cheerful & 4 & 3 & 2 & 1 \\
$\begin{array}{l}\text { 48. Is inattentive } \\
\begin{array}{l}\text { 49. Behaves in assertive } \\
\text { fashion }\end{array}\end{array}$ & 4 & 3 & 2 & 1 \\
\begin{tabular}{l}
50. Is impulsive \\
\hline
\end{tabular} & 4 & 3 & 2 & 1 \\
\hline
\end{tabular}

